\title{
Analysis of flow through channel with mounted blades
}

\author{
Łukasz Semkło ${ }^{1}{ }^{*}$ and Lukasz Gierz ${ }^{2}$ \\ ${ }^{1}$ Poznan University of Technology, Chair of Thermal Engineering, Poznań, Poland \\ ${ }^{2}$ University of Technology, Institute of Machines and Motor Vehicles, Poznań, Poland
}

\begin{abstract}
Numerical analysis of parts of the installation for transporting the mixture. The mixture consists of sand, stones and water. The analysis concerns the possibility of reducing the flow velocity of the mixture in the installation by means of installing the blades. The article presents an analysis of 10 blades that have been simulated. Speed distributions are presented after passing through the blades and determined which slows the speed of the mixture to the best possible extent.
\end{abstract}

\section{Introduction}

The suction dredgers are devices used to extract the aggregate from the bottom of the tank. The continuous increase in aggregate extraction in Poland requires manufacturers of dredgers to improve these machines. For the first 6 years since Poland joined the EU, aggregate production increased by over $100 \%$. Despite such a big increase, Poland produces less aggregate than the European average indicates. Our country is only $19^{\text {th }}$ in this respect behind the European powers such as Norway, Austria, Finland, Denmark, Sweden, the Netherlands and others. Forecasts for the coming years predict that the production of natural gravel aggregates will stabilize and slightly increase by launching new sites of exploitation and possible legalization of the places of their previous extraction without concessions. The growing cost of transport plays a special role and will be appreciated $[1,2,3]$.

The aim of the research was to develop a steering structure for the mixture of sand and gravel in the aspect of reducing the speed of moving particles. Optimizing the shape of the proposed blade should contribute to increasing the life of the rotor. The simulation tests carried out allowed to determine the most favorable shape of the working body. For the needs of these studies, the concepts of steering wheels of various shapes have been proposed and modeled. Each of these blades was placed $100 \mathrm{~mm}$ from the suction port of the pump. By concealing the various shapes of the steering wheels, it was assumed that they would constitute an obstacle to the transported mixture. Lower speed or lower impact force in the central part of the rotor will probably contribute to increasing its durability by changing the trajectory of the flow of a mixture of sand and gravel (previously you wrote gravel and water.

Figure 1 prezent drigger and figure 2 shown element in engine room wich was model.

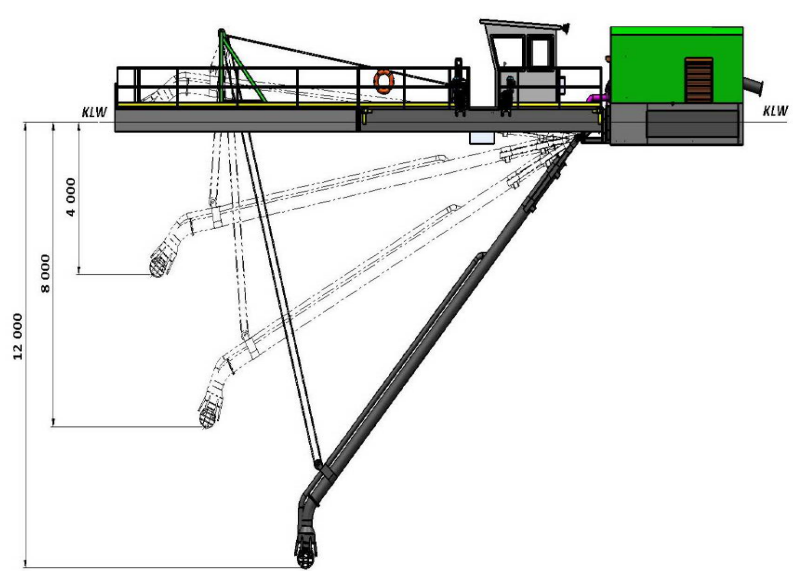

Fig. 1. Żwir-kop model ZK 10/8 300/250 dredger [4].

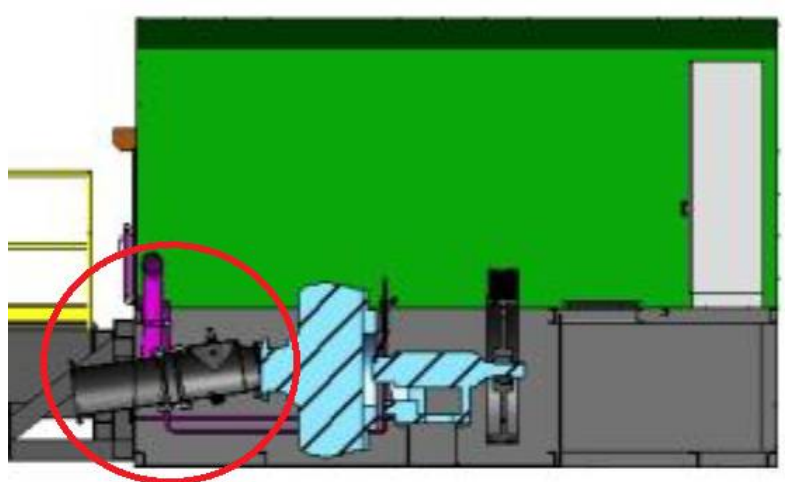

Fig. 2. The analyzed section of the engine room [4].

The Finite Volume Method was used for the research, which differs from the FEM method in that it is based on the analysis of the field variable behavior inside the grid cells, and not in the grid nodes. The FVM method consists in estimating the integral inside the cells of the grid or their mean values of the integral is divided by the cell volume. In subsequent time stages, by using the stream function, which flows through the volume

\footnotetext{
* Corresponding author: lukasz.semklo@put.poznan.pl
} 
elements of the model, field variables are updated. The space of the tested pipe was described by means of a grid, i.e. small sub-areas in the shape of tetrahedrons. This process is called discretization. The simulation was performed in the Ansys Fluent 16.0 program. The methods used in this program belong to the numerical fluid mechanics (CFD - Computational Fluid Dynamics) involving the flow of liquids, gases and related phenomena. $[5,6]$.

\section{Analysis and modelling}

For the purpose of this research, it is necessary to determine the parameters of a mixture of gravel and aggregate. First, the analysis of the grain size of the soil was made and then the specific density was determined in the next order. A detailed description of the methods used and a summary of the results obtained are described below. To determine the granulation or division into individual fractions, a shaker was used along with sieves of various mesh sizes. According to the Polish standard [9], we distinguish the following five factions:

- stony with grains $\mathrm{d}>40 \mathrm{~mm}$;

- pebble with grains $\mathrm{d}=40 \div 2 \mathrm{~mm}$;

- sand with grains $\mathrm{d}=2 \div 0.05 \mathrm{~mm}$;

- dust with grains $\mathrm{d}=0.05 \div 0.002 \mathrm{~mm}$;

- iowa with grains $\mathrm{d}<0.002 \mathrm{~mm}$. [7]

Analysis of the percentage composition of individual fractions of the mixture of sand and aggregate was carried out in laboratory conditions. For these tests, a representative sample of $696.91 \mathrm{~g}$ was taken from the bottom of one of the dumped water reservoirs, which was then dried at $90 \circ \mathrm{C}$ to $0.8 \%$ humidity.

\subsection{Numerical analysis}

The developed models of both the suction pipe and the steering wheel were imported into the Ansys program, in which they underwent discretization of the threedimensional space of the fluid (water with sand) using FVM. The next stage of the research was to determine the inlet and outlet connections so that the flow direction is known. After completing the grid creation process, the virtual model was moved to the simulation program. Before starting essential research, it was necessary to establish and task boundary conditions that are classified as follows:

o the aggregate expenditure at the level of $500 \mathrm{t} / \mathrm{h}$ based on data from the producer;

o specific gravity of aggregate $3.7 \mathrm{~g} / \mathrm{cm} 3$ - which was determined on the basis of completed tests;

o the speed at which the $5 \mathrm{~m} / \mathrm{s}$ spoil flows, based on data from the manufacturer;

o the share of the quartz mineral fraction in the mixture with water was about $15 \%$

o in order to simplify the research fraction sizes were adopted: $0.05 \mathrm{~m}$;

o length of the modelled pipe: $2 \mathrm{~m}$;

o diameter of the pipe: $250 \mathrm{~mm}$.
Figure 3 presents geometry of the pipe. Figures from 4 to 13 shows the geometry of blades.:

○ the aggregate expenditure at the level of $500 \mathrm{t} / \mathrm{h}$ based on data from the producer;

- $\quad$ specific gravity of aggregate $3.7 \mathrm{~g} / \mathrm{cm} 3$ - which was determined on the basis of completed tests;

○ the speed at which the $5 \mathrm{~m} / \mathrm{s}$ spoil flows, based on data from the manufacturer;

0 the share of the quartz mineral fraction in the mixture with water was about $15 \%$

$0 \quad$ in order to simplify the research fraction sizes were adopted: $0.05 \mathrm{~m}$;

- length of the modeled pipe: $2 \mathrm{~m}$;

o diameter of the pipe: $250 \mathrm{~mm}$.

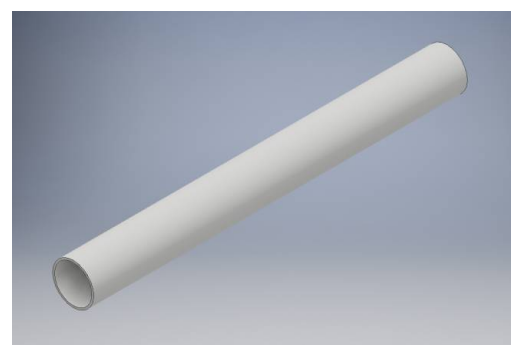

Fig. 3. The analyzed section of the engine room [4].

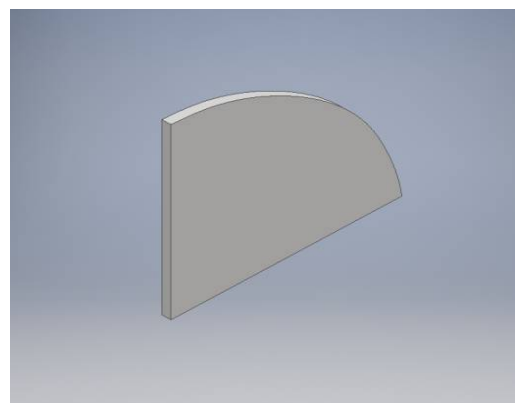

Fig. 4. The analyzed section of the engine room [4].

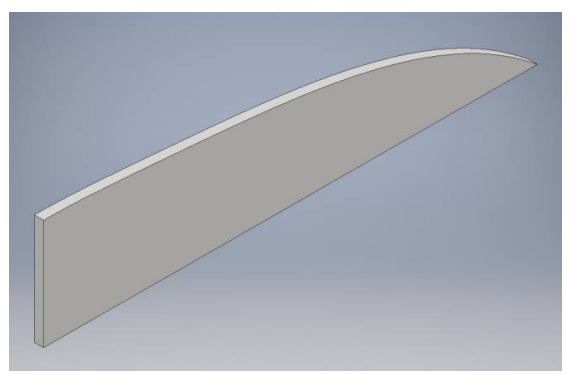

Fig. 5. The analyzed section of the engine room [4].

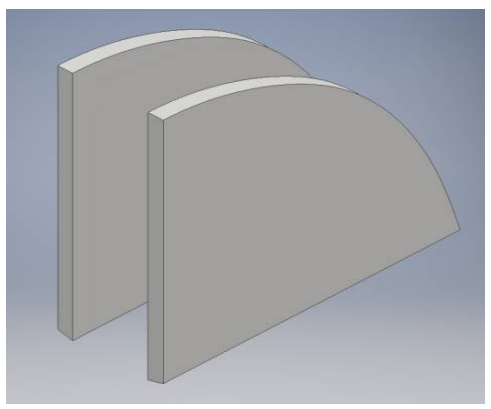

Fig. 6. The analyzed section of the engine room [4]. 


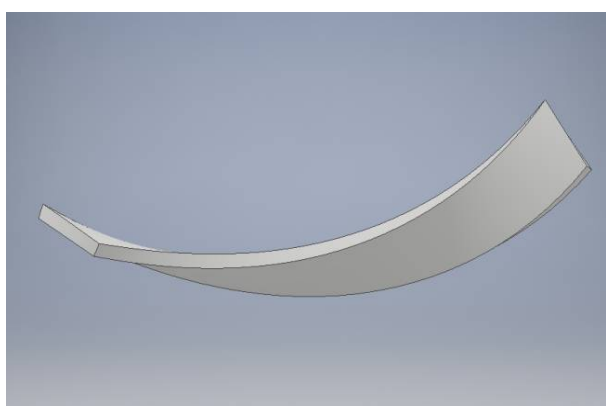

Fig. 7. The analyzed section of the engine room [4].

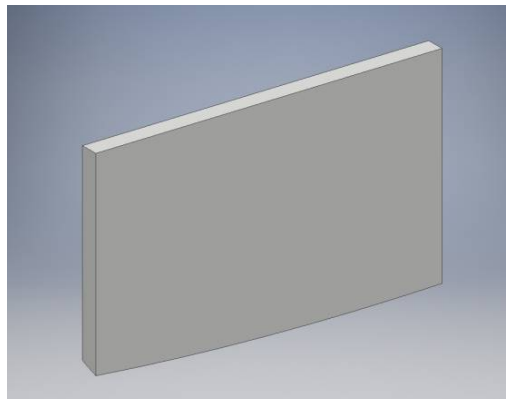

Fig. 8. The analyzed section of the engine room [4].

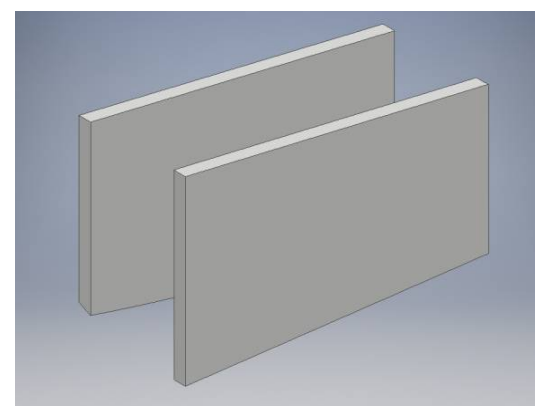

Fig. 9. The analyzed section of the engine room [4].

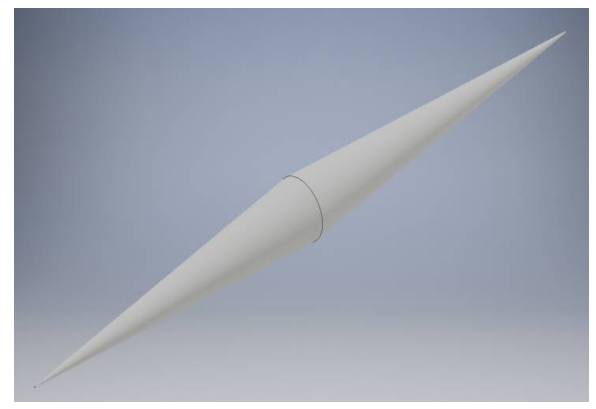

Fig. 10. The analyzed section of the engine room [4].

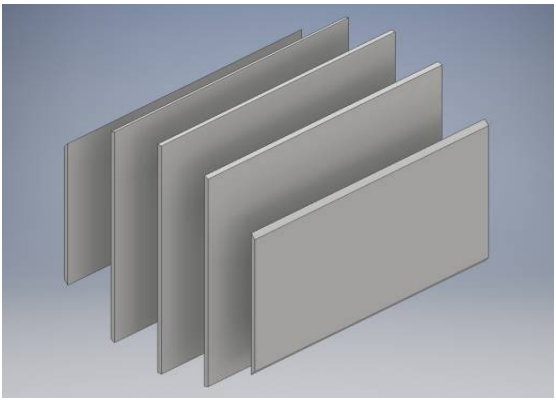

Fig. 11. The analyzed section of the engine room [4].

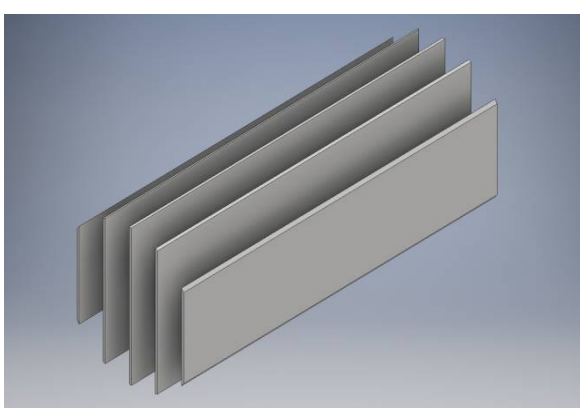

Fig. 12. The analyzed section of the engine room [4].

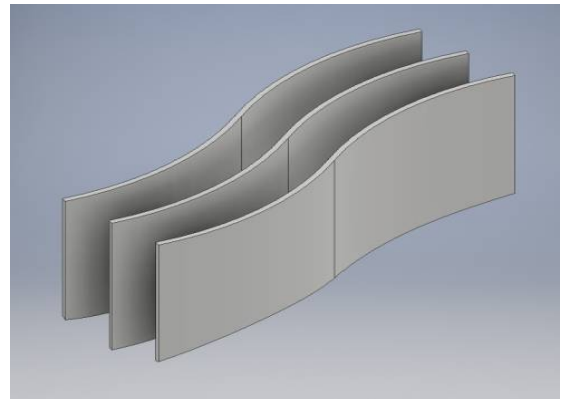

Fig. 13. The analyzed section of the engine room [4].

\section{Results}

As part of the simulation tests, the results of the trajectories of the moving particles before and after the collision with the hearth were obtained. The obtained test results do not take into account the direct collision between the molecules, because the overriding goal was to observe the reaction between the element controlling the particles of gravel and aggregate mixture.

The carried out studies of the flow of spoil in the suction dredger pipeline with the modelled vanes placed inside, allowed to analyze the velocity and trajectory of turbulence with which the tested mixture of water and aggregate hits the pump impeller. The tests were carried out for the pipeline without the blades and with all ten proposed blades. During the calculation, the mixture was given an initial speed of $5 \mathrm{~m} / \mathrm{s}$.

The flow without the working body is not disturbed and is shaped as it would be expected. At the outlet we notice a slight acceleration. The results are presented in Figures $14-34$.

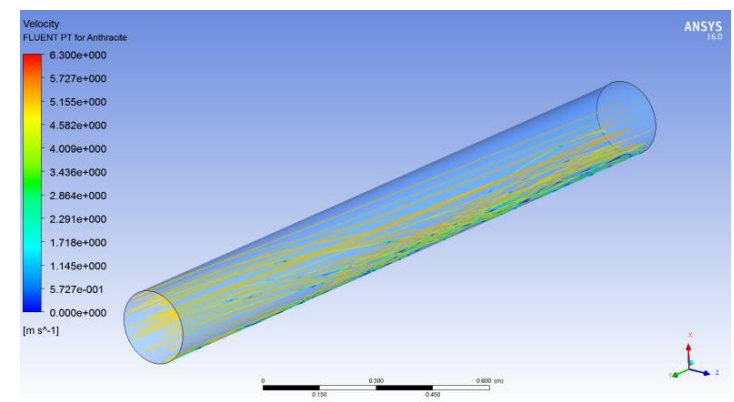

Fig. 14. Geometry without blade velocity distribution in the tube. 


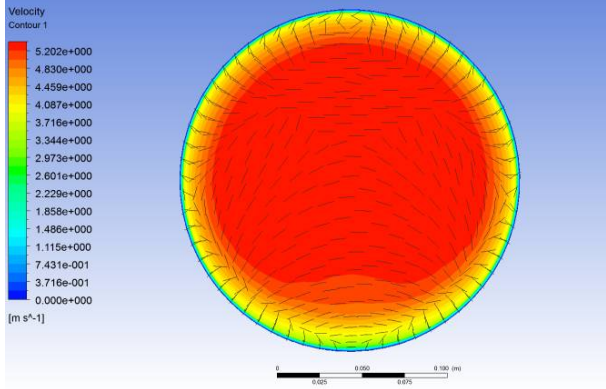

Fig. 15. Geometry without blade velocity distribution at the inlet of the tube.

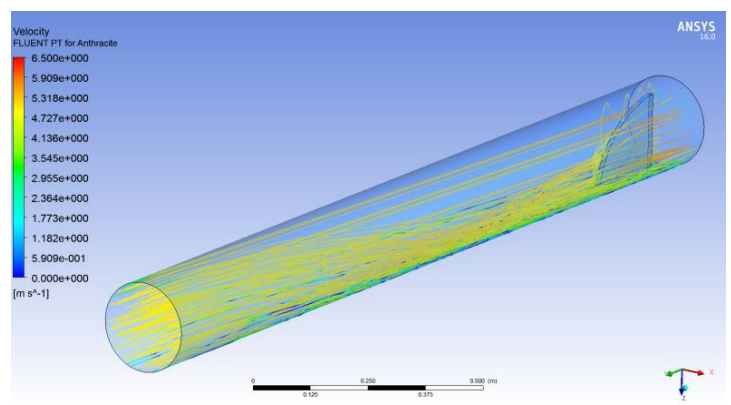

Fig. 16. Blade no. 1 velocity distribution in the tube.

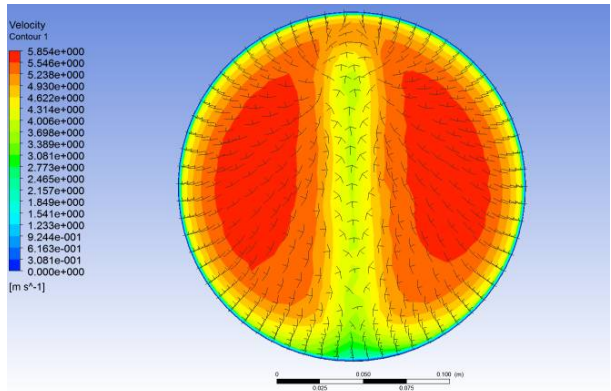

Fig. 17. Blade no. 1 velocity distribution at the inlet of the tube.

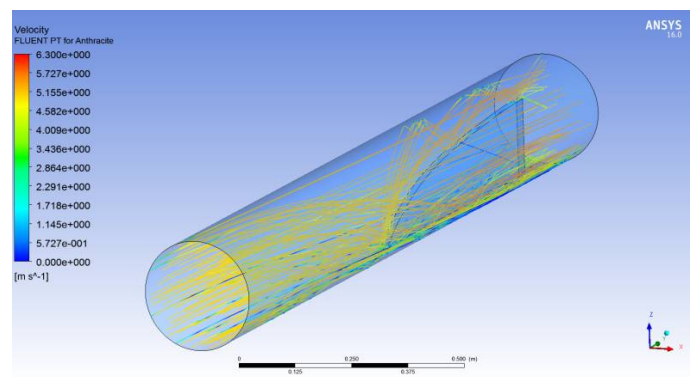

Fig. 18. Blade no. 2 velocity distribution in the tube.

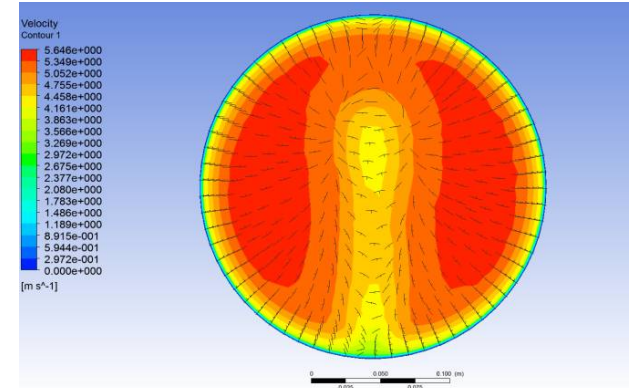

Fig.19. Blade no. 2 velocity distribution at the inlet of the tube.

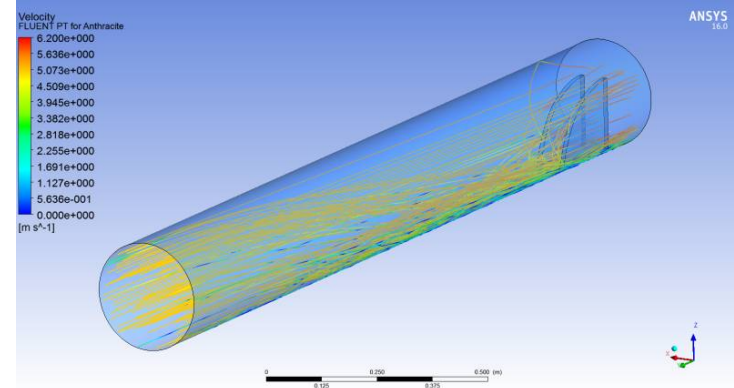

Fig.20. Blade no. 3 velocity distribution in the tube.

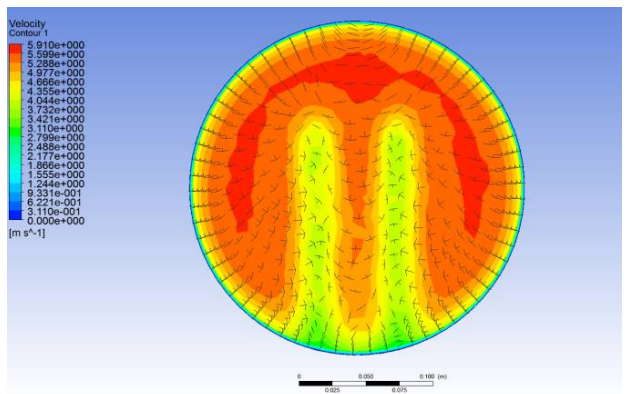

Fig. 21. Blade no. 3 velocity distribution at the inlet of the tube.

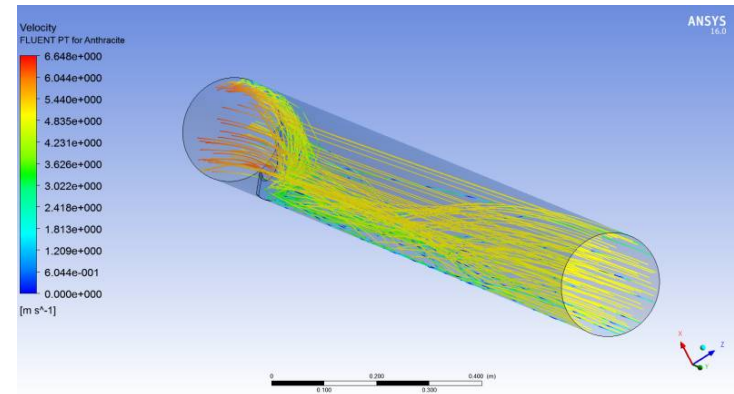

Fig. 22. Blade no. 4 velocity distribution in the tube.

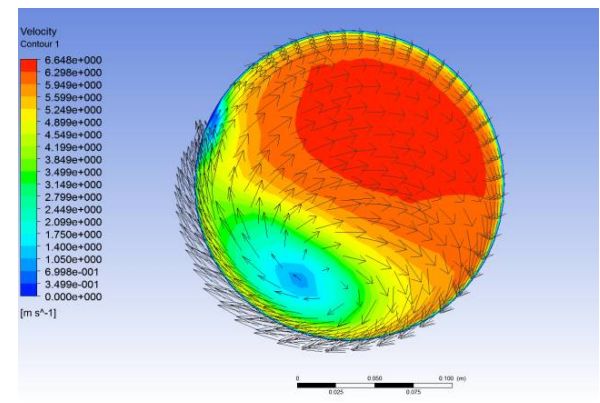

Fig. 23. Blade no. 4 velocity distribution at the inlet of the tube.

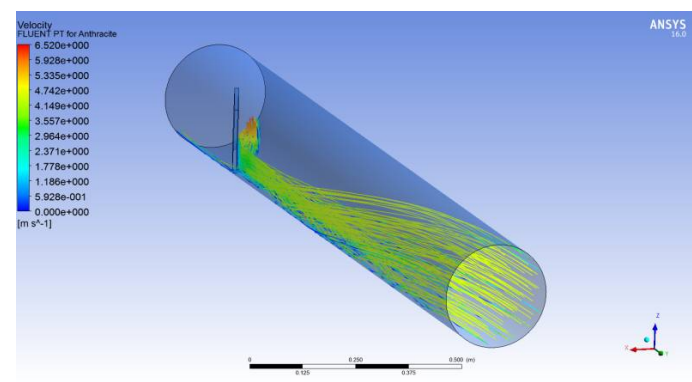

Fig. 24. Blade no. 5 velocity distribution in the tube. 


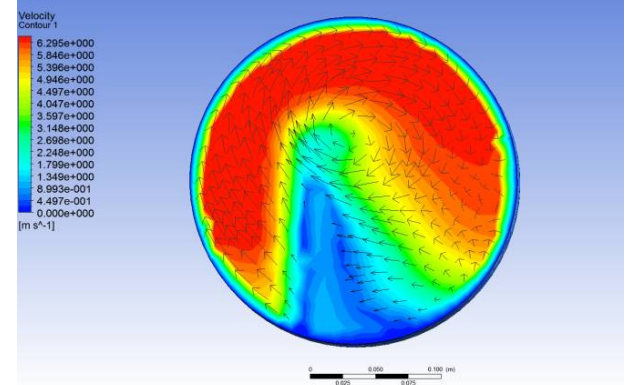

Fig. 25. Blade no. 5 velocity distribution at the inlet of the tube.

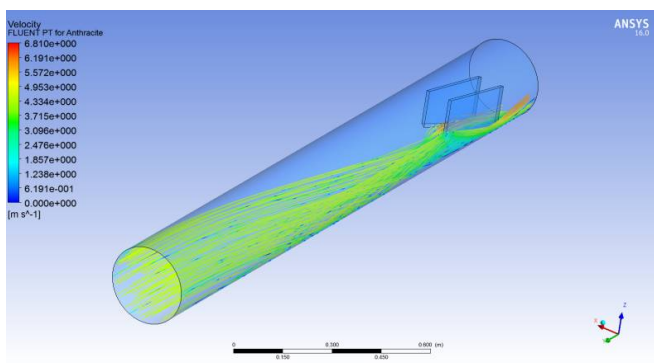

Fig. 26. Blade no. 6 velocity distribution in the tube.

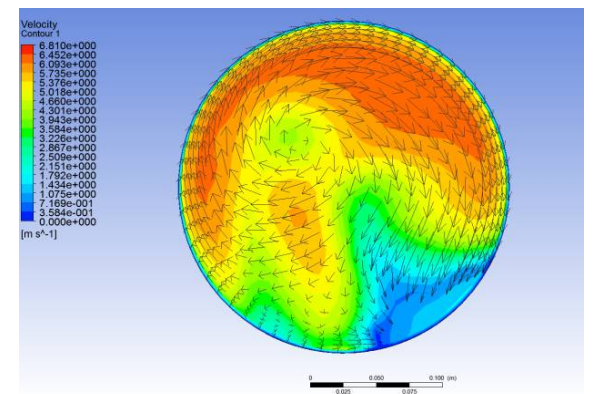

Fig. 27. Blade no. 6 velocity distribution at the inlet of the tube.

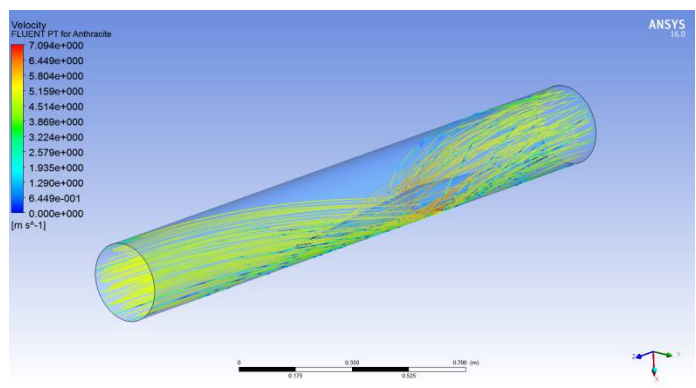

Fig. 28. Blade no. 7 velocity distribution in the tube.

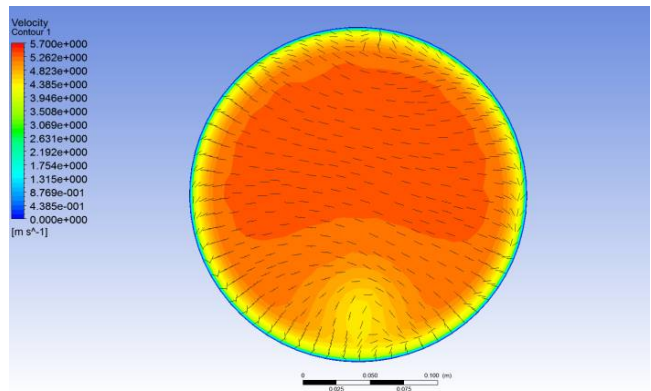

Fig. 29. Blade no. 7 velocity distribution at the inlet of the tube.

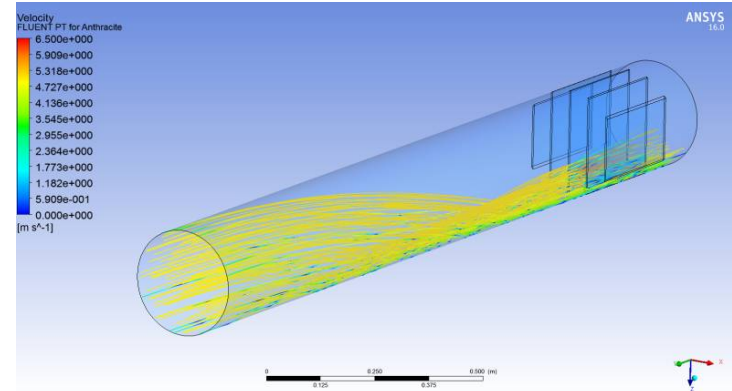

Fig. 30. Blade no. 8 velocity distribution in the tube.

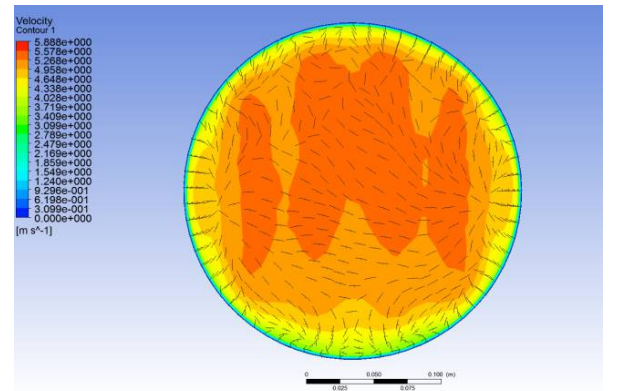

Fig. 31. Blade no. 8 velocity distribution at the inlet of the tube.

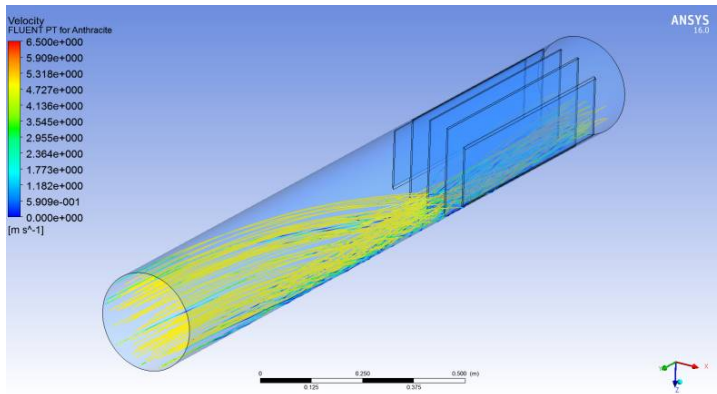

Fig. 32. Blade no. 9 velocity distribution in the tube.

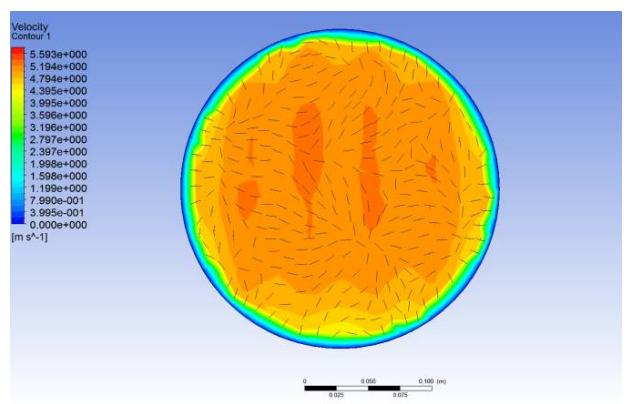

Fig. 33. Blade no. 9 velocity distribution at the inlet of the tube.

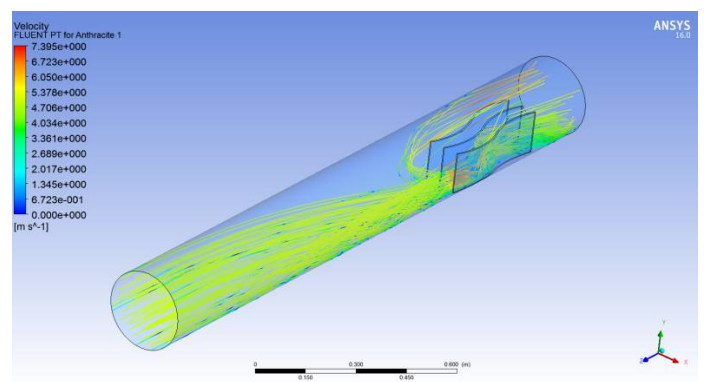

Fig. 34. Blade no. 10 velocity distribution in the tube. 


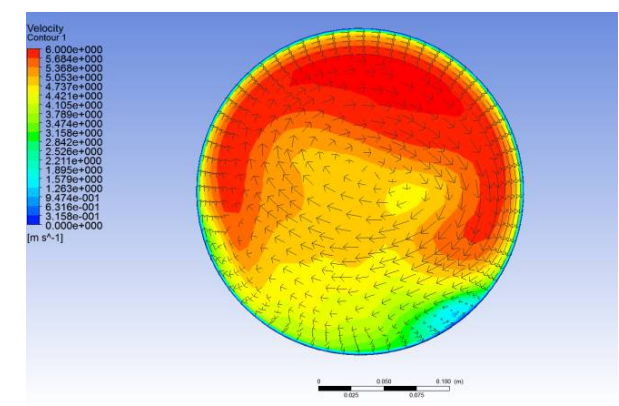

Fig. 35. Blade no. 10 velocity distribution at the inlet of the tube.

\section{Summary}

As a result of the conducted simulations, it can be concluded that the proposed shapes of blades numbered 7,8 and 9 best meet the assumed criteria. Model 8 gives optimistic results of the average speed of solids. In addition, the particle paths after impact with the control element have a favourable orientation.

The calculations did not take into account the collisions between molecules, therefore during the simulation of grains, which theoretically should hit each other, penetrate. Therefore, the speed results obtained after using the working organs may differ from the actual ones. In fact, after hitting the grain with a grain or other solid, both elements should lose speed. The only way to assess the behaviour of particles after collisions was to analyze the trajectory of particle movement.

\section{References}

1. S.F. Kim, F. Low, J. Film Cooling, 122, pp. 21-26, 1997

2. H. Schlichting, Boundary-Layer Theory $\left(7^{\text {th }}\right.$ edition, McGraw-Hill, New York, 1979)

3. A. Bęben, Maszyny i urządzenia do wydobywania kopalin pospolitych bez użycia materiatów wybuchowych (Wydawnictwo AGH, Kraków, 2008)

4. W. Kozioł, Ł. Machniak, Surowce i Maszyny Budowlane, nr 3 (2011)

5. http://www.imsdredge.com

6. M. Dudek, Dokumentacja techniczno ruchowa pogtębiara ssaca (refuler) (2016)

7. M. Kmiotek, Scientific Bulletin of Chelm, no. 1 (2008)

8. H. Kudela, Laboratorium numerycznej mechaniki plynów

(fluid.itcmp.pwr.wroc.pl/ znmp/dydaktyka/wzzmp/ WSTEP_LAB_NUM.pdf)

9. $\mathrm{PN}-86 / \overline{\mathrm{B}}-024 \overline{80}$ 